\title{
The Application of Information, Technology and Big Data in City Governance \\ - Take intelligent community construction in China as example
}

\author{
CHIU I FENG ${ }^{1, a}$ \\ ${ }^{1}$ Public Affairs School of Xiamen University, Xiamen, China \\ aallen0812@hotmail.com
}

\begin{abstract}
Keywords: intelligent community; information; technology; big data; city governance
Abstract. The rapid development of information and technology has promoted the arrival of the era of big data. It is no doubt that information, technology, and big data have stimulated the positive reforms in management field and made an important contribution on improving management efficiency and effect. It is worth noting that governments of different countries are making a positive response to this changes, and are fully applying information, technology and big data in government governance, social governance and community governance. In China, this combination product is the construction of "intelligent city" or "intelligent community", which is aiming at building a big data platform and management system through advanced information technology to make citizens fairly, effectively and rapidly access to information and enjoy public service, and make government become more efficient and transparent. This article describes the origin and development of intelligent community, analyzes the main characteristics of the intelligence community, especially summarizes on the operation structure of it. At last it points out the main problems of the intelligent community, and provides some suggestions for the future development.
\end{abstract}

\section{Introduction}

Information, technology and big data are leading the world into a new era, and changing people's way of life. As management tools, they not only have play a key role in the government management, but also become a key link in the government reforms around the world. Therefore, it is significant to study the practical effect and application of information, technology and big data from the perspective of government management. In China, from the early information openness and the government portal website construction to the electronic government and administrative service center construction, Chinese government has gradually expanded the application of information technology in government management, and has realized informatization in internal government and public service informatization in external government. Now, the task that government faces is how to realize the management informationization of the whole society, "intelligent city" and "intelligent community" are exploratory practice. As a minimum unit, the construction of "intelligent community" is becoming a breakthrough of local government's reform. This article describes the origin and development of intelligent community, analyze the main characteristics of the intelligence community, especially summarizes on the operation structure of it. At last it points out the main problems of the intelligent community, and provides some suggestions for future development.

\section{The rise and development of intelligent community}

As one part of the informatization strategy, the former vice president Gore of United States has put forward the concept of "digital earth" in 1998: "we need a 'digital earth', that is, a representation of earth with a multi-resolution and three-dimensional, adding geological data related to our planet on it" ${ }^{[1]}$ The concept of "digital earth" firstly reflects the combination of information, technology and big data with human life.

In 2008, the chief executive Mingsheng Peng of International Business Machines corporation (IBM) firstly put forward the new concept of "intelligent planet", which is also known as "smart planet", 
aiming at embedding and equipping sensors into different objects, such as electrical grid, railways, bridges, tunnels, roads, buildings, water supply systems, dams, oil and gas pipelines, and are widely connected to form the so-called "Internet of things", then connect all the "Internet of things" to realize the integration of human society and physical system. ${ }^{[2]}$ In 2009 , IBM sized the opportunity to hold 22 forums about "intelligent city" and communicated with more than 200 mayors and nearly 2000 government officials. After these forums, the concept of intelligent city was widely accepted by people and has attracted Nanjing, Shenyang, Chengdu, Kunshan and other cities to make strategic cooperation with IBM. In 2010, IBM officially put forward the vision of "intelligent city" and hope to make contribution to the development of China and the whole world. ${ }^{[3]}$ Based on the application of a new generation of information technology, "intelligent city" is defined in the IBM's white paper of "intelligent city in China" as: (1) comprehensive connection. Using intelligent sensing equipment to gather urban public facilities into net and induce core operation system of urban government in time; (2) full integration. "Internet of things" and Internet system is completely butt fusion; (3) encourage innovation, namely, government and enterprises take science and technology innovation based on the infrastructure of "intelligent city"; (4) coordinated operation. Different participants from key systems can collaborate efficiently.

Development so far, intelligent city has become the combination product of internet of things, cloud computing, mobile internet, other new generation of information technology and the needs of urban sustainable development. It also represents a new concept and a new model of urban development in today's world, reflects the integration of industrialization, information urbanization and agricultural modernization. To realize intelligent city, IBM has introduced a variety solutions, including intelligent power, intelligent health, intelligent transportation, intelligent supply chain, intelligent banks and so on.

City is the development product of human civilization, and the community is the basic part of city. As the urban survival and development carrier, the intelligent of community is the concentrated reflection of intelligent city. The construction of "intelligent community" aims at introducing concept of intelligent city into community, taking well-beings of citizens as a starting point and providing convenience for community citizens through building intelligent community to accelerate the construction of harmonious community and promote regional social progress. Seeing from the function, intelligent community takes community service as core task, provide residents with safe, efficient and convenient intelligent services and fully meet the resident's survival and development requirements.

Currently, there is no complete description about the definition of intelligent community. Most of the description focus on the technical level and emphasis on the intelligent community that is supported on internet of things and intelligent products. Chinese scholar Zhangpeng assured that intelligent community is a community with new management pattern based on a large-scale information intelligent process, forming by intelligent construction of residential buildings, household, medical treatment and community service through network communication technology such as Internet, Internet of things and sensor network. ${ }^{[4]}$ However, this definition also focus on technical level. On the contrary, the definition by Wang jingchun and others is more in line with" intelligent community", namely, the intelligent community should take enhancing the service level and strengthening management ability as the goal, according to the actual requirements and potential needs of citizens, management task of community and its development direction to make full use of information technology to realize intelligent of information acquisition, transmission, processing and application, and then establish modern community service and intensificated community management system, form the new mode of community with resource integration, suitable environment and great benefit. $^{[5]}$ 


\section{The main characteristics of intelligent community}

Taking Improving Community Governance Ability as Goal

Actually, intelligent community means to support and transform community service and management process by integrated application of modern science and technology. On the one hand, the application of the technology can make the community managers free from multifarious work and then greatly improve the efficiency and quality and save time to do more meaningful work. On the other hand, the application of the technology can perfect service process, increase the content of the service and management and reduce the waste of manpower from bull management, all these can make the residents get more comprehensive and thoughtful service. At the same time, the accuracy and efficiency of technology also can help the community to get more useful information and broaden horizons. The intelligent has made community work become more efficient, greatly reduced the situation with time consuming and inefficient and improved the management ability of community and capacity of service supplement.

Taking Continually Promoting Community Intelligence as stimulus

There are a large number of information related to population, environment, consumption and fire security in community every day. How to receive and handle these information is the core task of community. The intelligent community takes advantage in doing this and aims to acquire, classify, storage and handle these information timely and effectively, and analyze and forest residents 'status, behavior characteristics and service requirement from huge amounts of information through intelligent technology such as knowledge discovery and etc. In addition, intelligent system of intelligent community will also find the essence contents reflected by image information and the automation level of data center. It can further to optimize infrastructure and improve the efficiency of resource to realize the community resource sharing when technology and scale would reach a certain degree, and the integration of infrastructure and resource virtualization would become more mature.

Taking Guarantee Open and Dynamic of Information System as Base

It need to have a long-term plan, compatible ability, access ability and adapt ability in the construction and operation process of intelligent community. Open and dynamic are the indispensable features for intelligent community. Firstly, the technology that intelligent community relies on is in continuous development and need to update frequently. Secondly, the complex problems came from residents is changing every day, which needs flexible data system to solve these problems. Thirdly, as a basic unit in city, community needs advanced and open management system to adapt to various tasks from upper level institutions as well as service requirements from residents.

Taking Meet Citizens' Diversified Service Requirements as Core Task

Community is a linked group developing through life and culture interaction between community residents and community managers. Because the essence of intelligent community is to provide service for its residents, fully meeting diversified, humanized and personalized demands and requirements for residents through intelligent community featured by modern science and technology is very important. Firstly, the residents in the community can obtain and use the corresponding community resources through information sent by community system terminal. Secondly, community manager can change management means to provide better service to residents by informationization construction. At last, intelligent community can make the communication between residents and managers more effective and convenient, which is conducive to the development of the community.

\section{The Operation Structure of Intelligent Community}

The operation of intelligent community contains serveral related system(See Figure1), the following figure shows the systems and processes of intelligent system. 


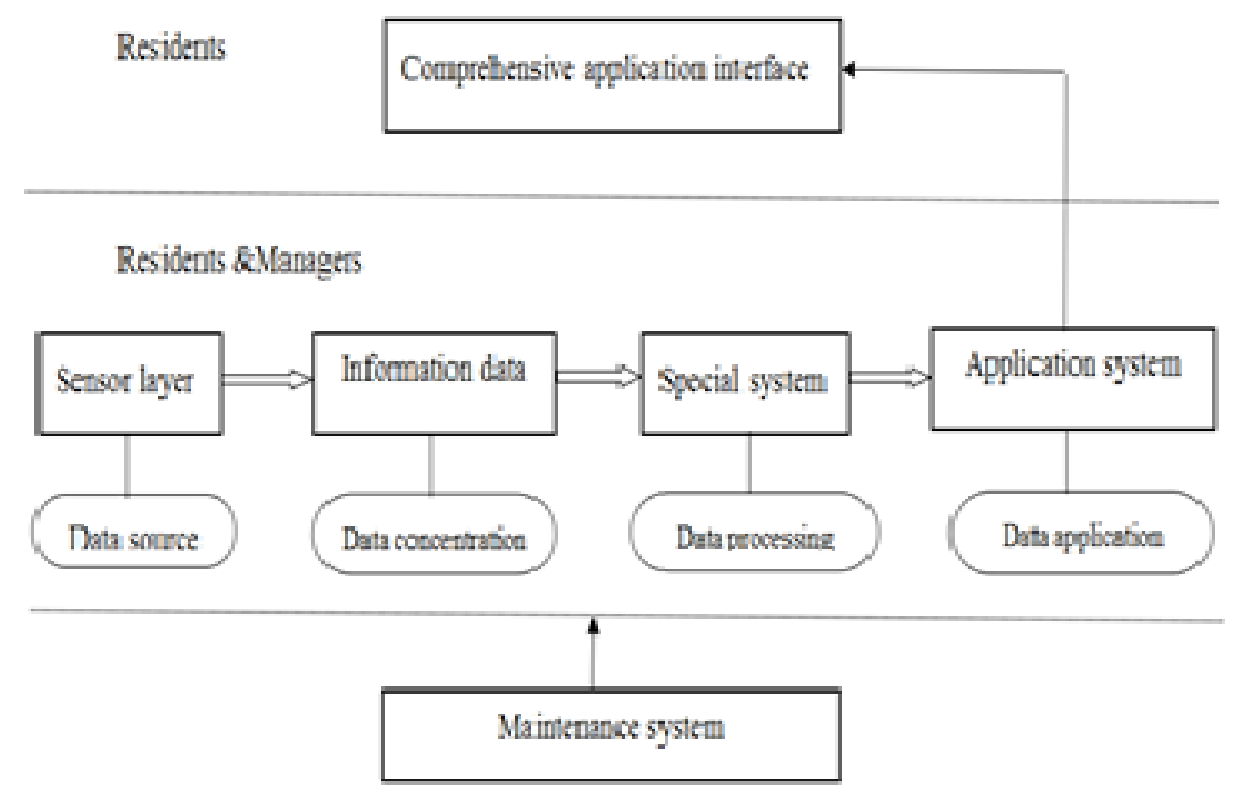

Figure1 The operation structure of intelligent community

\section{The problems existing in intelligent community construction}

The Imbalanced Development of Intelligent Community

First of all, the development of intelligent community is imbalance from region to region. Due to the high cost of intelligent community construction, and other effects such as economic level and consumption level, the development of the intelligent community in China is imbalance between different regions and cities. The intelligent communities is mainly constructed in developed cities and coastal cities, such as Beijing, Shanghai, Shenzhen, and Guangzhou. Second, there is digital divide between communities and residents. The different capacity to receive information and culture degree between residents, couple with different economic level between communities have made the significant digital in their ownership in the information product (equipment) and the use of information technology. At the same time, the different understand and demand of intelligent service between different residents make they choose different service means and methods, which has caused this part of residents cannot become the true users and the beneficiary of intelligent community.

The Lack of Effective Guarantee Mechanism

First, the lack of effective top-level design. At present, there is no clear academic definition on intelligent community as well as uniform design and construction standards in China. Therefore, China has not formed the universal basic framework of service system of intelligent community. Second, the products and technology solutions of intelligent community are not yet mature. Although there are community applications combined with the internet of things, they all still in the pilot phase, and the application requirements are not enough and has not realize interconnection between terminals and service systems. On the other hand, due to high cost of intelligent products, one part of communities and residents cannot join in the intelligent community. Third, the lack of proper operating mode. Because the intelligent community proposed time is shorter, the service mechanism is not sound, and the support capability is not strong. Hence, the social participation mechanism remains to be perfect. The existing Beijing model, Guangzhou model and Hangzhou model have different characteristics with different advantages and disadvantages. Therefore, effective operation mode is still need to be explored by participants of the whole industry chain.

\section{Low Degree of Integrated Service System}

First, the access to information of service system in intelligent community is single. At present, the most intelligent communities are still in the primary stage. The residents are mostly connect service platform by smart cards, visual telephone and community public service terminals. However, they are 
unable to realize the multi-channel, multi-type, and convenient remote mobile service. Second, the low level of intelligent community service provision. Currently, intelligent community system can only provide limited and basic service. The incomplete module construction of foundation platform and function application layer have led to the low efficiency of information interaction and service provision. In addition, the poor compatibility and openness of intelligent products have increased the difficulty to manage and maintain equipment and system, as well as bring a lot of inconvenience to system integration and data sharing in the future. Third, different communities service platform are developed alone. Intelligent community service platform are basically separated custom only with community characteristics and cannot achieve a wide range of coverage. System operating cost is high and the repeat development and utilization of the space is lesser.

The Lack of Corresponding Management and Service Talents

The management and operation of intelligent community requires a lot of technical expertise, management talents and general information professionals. However, the managers in existing communities are older with low education, they have no capacity to use technology and handle information system.

\section{The suggestions to perfect intelligent community}

Government in China should take actions to enforce the construction of intelligent community, the following steps and suggestions can be useful.

Perfect Intelligent Community Service Infrastructure to Achieve Resource Sharing

Government should first choose the appropriate layout and reasonable construction ways according to the geographical conditions, the specific situation of the community population, efficiency of service facilities, requirements of residents and development trend of community in the future. Furthermore, government should encourage communities to build "integrated network" service platform that is consist of telecommunication network, Internet and television to maximize the development and utilization of resources, so as to realize the full use of data resources, information resources and infrastructure resources of intelligent community.

Promote the Construction of Communication Network Facilities and Community Perception Network

On the one hand, it need to speed up the wireless network construction, such as wireless LAN, WIFI and $3 \mathrm{G}$ and actively promote integration and transformation of digital network to build communication network to adapt to a new generation of high definition TV and transport demand of IPTV. The last goal is to construct a seamless information network that can cover private house and public space. On the other hand, government should promote the construction of community security perception network, strengthen the construction of video surveillance network and visual access network, and speed up building a network of environmental perception to strengthen the community's perception of the street light, noise, waste and air condition.

Set Up a Learning and Promotion Model for Intelligent Community

Based on the study of community service platform, government should choose reasonable community service model and construct community service platform that can meet regional environment and lifestyle characteristics. Government can set up demonstration plots for intelligent community for 2-3 years in cities with different models, such as the developed urban community with young, retirement community with elders, the integration community with of urban and rural population and the island or mountain community. In addition, government should learn experience and suggestions from local residents and management departments, and summarize lessons to create better intelligent community.

Cultivate Professional Talents for Intelligent Community 
First, community should equip with a certain number of professional social workers through public recruitment according to the needs of actual work situation. Second, community should improve the personnel policy, actively develop the service jobs for intelligent community, employ different levels of professional personnel to provide community service and optimize the talent structure of intelligent community. Third, community should strengthen funds input for talents training and encourage talents to improve their professional knowledge and community work service level. At last, government should perfect incentive system, and improve the level of salary and welfare of community managers.

Strengthen Security System of Intelligent Community

First of all, strengthen the legal guarantee. At present, government should constantly improve the relevant policy support system to ensure the intelligent community construction smoothly, and establish and perfect the system of laws and regulations. At the same time, government should create a favorable legal environment for the development of intelligent community and effective maintenance of intelligent community construction. Second, strengthen financial security. Government should increase financial capital investment and attract and encourage private capital, financial capital, and international capital to invest intelligent community construction in the process of intelligent community construction.

\section{References}

[1] Gore. Digital earth's understanding of the 21 st century human planet. Earth information, Vol. 2(1998)

[2] Mingsheng Peng. Intelligent planet. [EB/OL]. http://www.ibm.com/smarterplanet/cn/zh/overview/ideas/index.tml?re=spf.

[3] Wangyang. The better tomorrow of "intelligent city". Journal of Chinese computer users, Vol. 17(2009)

[4] Zhangpeng, Wang Yibing,Sheng Yumei and Li Ruosi. Resaerch on intelligent community construction through integrated information service platform. Chinese management informationization, Vol. 6(2012)

[5] R. Wang jingchun, Gao bing, Lei yanxu, Fang huaying and Gao fei."Analyze on definition and application of intelligent community". Journal of socialist theory guide,Vol. 5(2012) 